\title{
A New Dynamic Fracture Plugging Evaluation Method and Its Application in Cementation for Mudstone and Sandstone Formation with Narrow Pressure Range in China South Sea
}

\author{
Jianglin Zhu ${ }^{1,3}{ }^{\text {, }}$, Jiangxiong Wei ${ }^{1}$, Qijun $\mathrm{Yu}^{1}$, Mingbiao $\mathrm{Xu}^{2}$, Yuwei Luo ${ }^{3}$ \\ ${ }^{1}$ School of Materials Science and Engineering, South China University of Technology, Guangzhou, P. R. China \\ ${ }^{2}$ Petroleum Engineering College, Yangtze University, Wuhan, P. R. China \\ ${ }^{3}$ China Oilfield Services Limited Oilfield Chemicals Division, Zhanjiang, P. R. China
}

Email address:

jianglinzhu123@163.com (Jianglin Zhu)

${ }^{*}$ Corresponding author

To cite this article:

Jianglin Zhu, Jiangxiong Wei, Qijun Yu, Mingbiao Xu, Yuwei Luo. A New Dynamic Fracture Plugging Evaluation Method and Its Application in Cementation for Mudstone and Sandstone Formation with Narrow Pressure Range in China South Sea. International Journal of Science, Technology and Society. Vol. 7, No. 2, 2019, pp. 33-37. doi: 10.11648/j.ijsts.20190702.11

Received: April 7, 2019; Accepted: May 29, 2019; Published: June 12, 2019

\begin{abstract}
One of the difficulties in high temperature and high pressure wells and deepwater well cementation in China South Sea is that the pressure range is very narrow. In the drilling or cementation process, the formation is easy to form sharp crack leakage. In general, the traditional simulation of bottom-hole mud or cement slurry leakage is to use the mesh plate or fixed width at a certain temperature and pressure difference. However, when there are wedge cracks in the formation, it will cause repeated "huff and puff" dynamic leakage of fluids. Dynamic leakage puts forward higher requirements for evaluation methods and plugging materials. In view of the problems, a new dynamic fracture plugging evaluation instrument was developed, and the new hydraulic wedge plugging material and matching cementing technology were optimized, which solved the problem of cement slurry leakage and return in China South Sea. The results of this paper have been successfully applied in cementing operations of high temperature and pressure wells and deepwater wells in the China South Sea, effectively solving the problem of hydraulic wedge leakage in sandstone formation cementing with narrow safety pressure window.
\end{abstract}

Keywords: Dynamic Fracture, Plugging, Deepwater, High Temperature and High Pressure, Cementation

\section{Introduction}

There is rich in oil and gas resources in China South Sea, and Yingqiong basin in the China South Sea is one of the three major high-temperature and high-pressure zones. One of the difficulties in high temperature and high pressure wells and deepwater well cementation is that the pressure range is very small. The strata in the China South Sea are mainly composed of mudstone and sandstone. In other words, when the annular liquid column pressure is greater than the formation fracture pressure, hydraulic wedge will occur, resulting in fracture leakage and even not returning. It may easily lead to oil and gas reservoir leakage seal, oil and gas channeling, and even cause well control problems after cementation $[1,2]$.
The traditional evaluation methods of cementation slurry plugging ability are mainly slotted plate method and sand plate method [3, 4]. The characteristics of these two evaluation devices are fixed slit width or hole diameter, which is independent of the annular liquid column pressure. However, after the actual formation fracture, the greater the liquid column pressure is, the larger the crack width will be. The cement slurry in the dynamic fracture will repeatedly "huff and puff" dynamic leakage along with the fluctuation of pressure in the well [5]. Therefore, although the traditional method to evaluate the ability of cement slurry plugging has certain reference value, it cannot truly simulate the effect of the formation plugging. Traditional cement plugging materials are mainly large-particle bridging materials and composite materials of soft winding fibers [6-9]. Its disadvantages are that large particles, easy to plug the narrow 
annulus gap; large particle composites attached to the crack near the mouth, in the crack "one and one" of the "huff and puff" effect is easy to spit out, pointed crack plug reliability is poor.

In view of the problems in the above evaluation methods and materials, a new evaluation instrument that can dynamically simulate the hydraulic wedge fracture plugging was developed, and the new hydraulic wedge plugging material and supporting cementation technology were optimized based on the evaluation instrument. The research results have been successfully applied in well A in the west of the China South Sea, and have been widely applied in cementation operations of high-temperature and high-pressure wells in the China South Sea and ultra-deep wells in the China East Sea with narrow pressure range, effectively solving the problem of hydraulic wedge leakage in mudstone and sandstone formation.

\section{Development of Dynamic Fracture Plugging Evaluation Instrument}

The design idea of dynamic fracture plugging evaluation instrument is to simulate the "breathing effect" of formation fractures through the interaction of positive pressure and back pressure, so as to achieve the effect of dynamic fracture change. Its main purpose is to make the whole experimental results more true to reflect the formation leakage state, compared with the conventional instrument, the test results appear more scientific.

\subsection{Structural Components}

Figure 1 is the equipment photo of the dynamic fracture plugging evaluation instrument, which simulates the dynamic change of formation fracture size with the fluid column pressure in the well. The evaluation instrument is mainly composed of transmission device, pressure supply device, adjustment mechanism and metering device. The transmission device is composed of a conical plug, a connecting rod and a piston. The upper conical plug is located in the body of the leakage cavity and extends the live part into the drive cavity through the connecting rod that can move up and down. The pressure supply device is composed of a nitrogen source, a pressure regulating valve and a pressure gauge. The pressure source is input into the driving chamber through the driving pressure inlet, which ACTS as the driving pressure for the upward movement of the piston to simulate the formation fracture pressure. The regulating mechanism, namely the screw rod, is located at the upper end of the drive cavity, and contacts the lower part of the piston of the drive mechanism when the pressure supply device is not supplied. By adjusting the lower limit of piston motion stroke, the maximum annular leakage gap after crack opening is obtained by simulating the maximum clearance of the crack roar. The metering device, the measuring cylinder, measures the volume of liquid flowing out of the leakage liquid outlet of the leakage chamber.

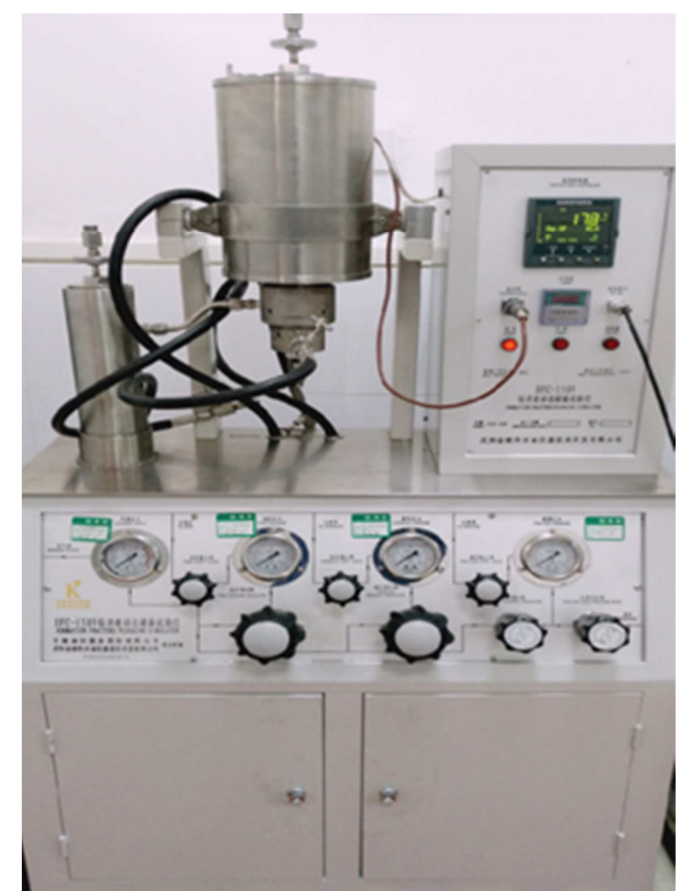

Figure 1. Equipment photo of dynamic crack sealing device and.

\subsection{Working Principle}

When the pressure of the plugging slurry cavity is greater than that of the driving cavity, the linkage mechanism moves downward under the pressure difference and the annular leakage gap. After slurry leakage, the pressure difference decreases, the linkage mechanism moves upward, and the width of leakage seam becomes narrow. The pressure difference becomes larger after narrowing, and the linkage moves downward again. The annular leakage gap is so "one piece and one close" until the plugging slurry is completely blocked or completely leakage. If the plugging effect of the leakage slurry is good, the pressure difference between the leakage slurry cavity and the leakage cavity is large and the leakage is small. On the contrary, the pressure difference is zero, all the slurry leakage.

\subsection{Test Procedure}

Hydraulic wedge crack roar setting: adjust the lower limit of motion stroke of linkage mechanism according to the maximum annular leakage required by test. Generally, the width of slurry leakage seam is set as $0.5 \sim 1.0 \mathrm{~mm}$.

Grouting: disconnect the test pressure valve, adjust the pressure supply device, and simulate the fracture pressure of $1 \mathrm{MPa}$ to make the linkage move upward under the action of driving pressure, and the width of leakage gap is zero; Remove the upper cover of the plugging slurry chamber and install the upper cover after injecting the plugging slurry.

Test: the test pressure valve is connected, and the test pressure from the pressure supply device is gradually input into the plugging slurry cavity under the action of the throttle speed limit to simulate the liquid column pressure. Gradually increase the liquid column pressure, respectively test the same volume of plugging paste in different gap width of the 
pressure difference.

\section{Optimization of Cementing Materials for Hydraulic Wedge Fracture Plugging}

Grainy plugging materials commonly used in cement slurry are hard asphalt, perlite, walnut shell, carbon black, cellophane, fibers, nylon (short fibers). However, in actual use all sorts of problems, such as using the hard asphalt, downhole temperature should not exceed $100^{\circ} \mathrm{C}$; However, walnut shell materials are prone to cause casing blockage [10, 11]. With the development of cement slurry leakage control technology, long fiber has gradually emerged as a cement slurry plugging material, and has been widely used in the field. Conventional cement slurry is mixed with long fiber to form a plugging cement slurry system [12-14]. The system has the following characteristics [15, 16]: (1) A network bridge is formed at the crack at the bottom of the well, which helps to produce the required filter mesh and corresponding filter cake; (2) fiber cement slurry is suitable for all temperature and cement slurry density conditions, with all cement slurry additives and most of the cement slurry formula compatibility; (3) the fiber is an inert material. In the slurry mixing tank, the fiber material is continuously added to the cement slurry, which is easy to be dispersed and will not block the slurry tank and circulation pipeline.

Through the repeated simulation test of dynamic fracture plugging instrument, the white cluster fiber B62 and particle size distribution plugging material B69 are optimized. The plugging capacity of $\mathrm{B} 62$ and $\mathrm{B} 69$ is shown in table 1. Recommended dosage: $\mathrm{B} 62$ is $0.5 \% \sim 1 \%$ (BWOC), and B69 is $3 \% \sim 6 \%$ (BWOC).

Table 1. Dynamic crack plugging effect of B62 and B69 in lost circulation material.

\begin{tabular}{|c|c|c|c|c|}
\hline The biggest cracks(mm) & $\begin{array}{l}\text { B62 added amount in } 600 \\
\text { ml plasma(g) }\end{array}$ & $\begin{array}{l}\text { B69 added amount } 600 \mathrm{ml} \\
\text { plasma(g) }\end{array}$ & $\begin{array}{l}\text { Pressure on the pressure difference } \\
\Delta \mathrm{P}(\mathrm{MPa})\end{array}$ & Conclusion \\
\hline \multirow{4}{*}{0.25} & 0 & 0 & 0 & Failure \\
\hline & 4.0 & 0 & 5 & Successful \\
\hline & 0 & 24 & 0 & Failure \\
\hline & 2.4 & 12 & $>7$ & Successful \\
\hline \multirow[b]{2}{*}{0.5} & 4.0 & 0 & 3 & Failure \\
\hline & 2.4 & 12 & 6.5 & Successful \\
\hline 1.0 & 4.0 & 24 & 6.5 & Successful \\
\hline
\end{tabular}

Note: the experimental temperature is $30^{\circ} \mathrm{C}$, water, the mud density is $1.40 \mathrm{~g} / \mathrm{cm}^{3}$. Formula: sea water $+\mathrm{G}$ class cement $+25 \%$ reinforcer $+20 \%$ lightening agent $+0.5 \%$ defoamer $+5 \%$ water loss agent $+1.5 \%$ dispersant $+1.3 \%$ retarder + plugging material.

It can be seen from the experimental results in table 1 that the cement slurry system mixed with B62 and B69 can effectively block the dynamic fractures below $1.0 \mathrm{~mm}$ and increase the wellbore pressure by more than $6.5 \mathrm{MPa}$. This is because the B62 fiber material is similar to the "steel bar" in concrete, which is evenly distributed into the cement slurry and has a good supporting and framing effect. At the same time, the cement particles and the plugging material B69 were wound by the fiber, which further enhanced the internal structural force of the slurry. B62 plugging material is by 30 80 mesh of different size particles of material, grading of particles can better sealing cracks in the roots, the root of the hydraulic wedge block cracks as to enhance the formation pressure, compared with the traditional patching materials, not easy blocking narrow annulus, not easy from a crack in the spit, its effects are more reliable, is advantageous to the narrow window safety pressure mud sandstone formation cementing.

\section{Application Effect}

\subsection{Application in High Temperature and High Pressure Wells in Yingqiong Basin}

In the Yingqiong basin at China South Sea, the well depth of well A is $3975 \mathrm{~m}$, the main purpose layer pressure coefficient is $2.19 \sim 2.22 \mathrm{~g} / \mathrm{cm}^{3}$, the bottom-hole static temperature $158^{\circ} \mathrm{C}$, using "casing $\Phi 762.00 \mathrm{~mm}+\Phi 508.00$
$\mathrm{mm}+\Phi 355.60 \mathrm{~mm}$ casing pipe $+\Phi 298.45 \mathrm{~mm}$ liner + $\Phi 273.05 \mathrm{~mm}$ x $\Phi 298.45 \mathrm{~mm}$ liner $+\Phi 177.80 \mathrm{~mm}$ alternate liner+ $149.23 \mathrm{~mm} \Phi$ spare hole" of well bore structure. Including $\Phi \times 273.05 \mathrm{~mm} \Phi 250.83 \mathrm{~mm}$ composite casing well section and the upper tail pipe $\Phi 298.45 \mathrm{~mm}$ liner overlap long $726 \mathrm{~m}$, at the bottom of the pressure coefficient is $2.04 \mathrm{~g} / \mathrm{cm}^{3}$, pressure window this interval is only 0.08 $\mathrm{g} / \mathrm{cm}^{3}$, after the casing running cycle back to the displacement of $0.29 \mathrm{~m}^{3} / \mathrm{min}$.

The cement slurry with a density of $2.2 \mathrm{~g} / \mathrm{cm}^{3}$ was selected as the basic formula in the experiment. When temperature is $90^{\circ} \mathrm{C}$, under different pressure regulation, determination of different varieties in this paper, research and development of dynamic plugging imager plugging material plugging effect of cracks, optimizing the plugging material B69, B62. Plugging material B69 is mixed with silica powder and cement, and B62 is mixed with pump during cementing. Use one piece centralizer to raise casing to medium; control casing speed to prevent malignant leakage; casing double rubber plug cementing, pumping high efficiency oil-based flushing fluid and isolation fluid, low speed mixed water slurry. Monitoring data show that the leakage velocity is $7.15 \mathrm{~m}^{3} / \mathrm{h}$ before the cement slurry is put out of the casing shoe. $1.3 \mathrm{~m}^{3}$ plugging cement slurry after the pipe shoe, leakage stop; Before the rubber plug is pressed, the pump pressure is $6.05 \mathrm{MPa}$, which is basically consistent with the design value of $6.1 \mathrm{MPa}$, and the cement slurry returns to the 
design position. After cementing, the equivalent of floor drain test was $2.27 \mathrm{~g} / \mathrm{cm}^{3}$, which was consistent with the geological prediction. Annulus casing pressure is zero; the pressure test was conducted at $7 \mathrm{MPa}$, and the annulus liquid column pressure exceeded the upper pipe shoe leakage pressure at $3.5 \mathrm{MPa}$, with stable pressure and good sealing quality of annulus cement.

\subsection{Application of Deepwater Surface Cementing in the China South Sea}

The depth of well B in the China south sea is about $997.0 \mathrm{~m}$, and the designed well is $4432.0 \mathrm{~m}$ (vertical altitude). Mud on the seabed line temperature of about $4^{\circ} \mathrm{C}$, bottom hole temperature $141.4^{\circ} \mathrm{C}$. The design depth of the 26 "surface hole is 2,105 meters, and the 20" casing is 2,100 meters for cementing. This interval strata are mainly composed of mudstone with sandstone, and the fracture pressure is low, operation window is small, there is great risk of leakage of underground, and at the same time considering the shallow geological disasters, slow strength development in low temperature and other issues, the first pulp slurry system chose low dense anti-channeling artificial beads $1.40 \mathrm{~g} / \mathrm{cm}^{3}$, tail slurry with high strength and $1.85 \mathrm{~g} / \mathrm{cm}^{3}$ double coagulation slurry in cementing. The proportion of the synthetic base drilling fluid system was $1.03-1.08 \mathrm{~g} / \mathrm{cm}^{3}$, displacement rate was $7 \mathrm{bpm}$ for software simulation, and the pressure window of the 26 "well segment was only $0.06 \mathrm{~g} / \mathrm{cm}^{3}$.

Plugging materials B69 and B62 were added into the preflush liquid system and cement slurry. The additional amount of cement slurry can be determined by the reverse calculation of cleaning thick slurry after drilling and pumping the display liquid to ensure the return height to the design position. At the same time, ECD distribution in the whole well is simulated by software to control it less than formation leakage equivalent. The pump pressure is normal during the whole cementing process. The ROV observes the wellhead and returns normally. There is no reflux after cementing. At the later stage, the maximum casing pressure was $1500 \mathrm{psi}$, and the test pressure was $1.35 \mathrm{~g} / \mathrm{cm}^{3}$, which met the requirements of the next drilling.

Subsequently, this technique was extended to cement more than ten high temperature and high pressure wells in the China south sea and ultra-deep wells with narrow pressure range in the China east sea, effectively solving the problem of hydraulic wedge leakage in mudstone and sandstone formation.

\section{Conclusion}

1) A new dynamic fracture plugging evaluation instrument is developed. Compared with the traditional cement slurry plugging capacity evaluation, it is an improvement and innovation. It can effectively evaluate the plugging capacity of plugging slurry under the dynamic change of hydraulic wedge fracture width.

2) The plugging slurry with composite plugging materials B62 and B69 can effectively plug the root of hydraulic wedge fracture and improve the bearing capacity of sandstone formation.

3) The research results have been successfully applied in cementing of more than 10 wells in China South Sea, such as high temperature and high pressure wells and deepwater wells. It effectively solves the problem of hydraulic wedge leakage in cementing of mudstone and sandstone formation with narrow safety pressure window, and has good application value.

\section{References}

[1] Xiao Yao, Baozhong Zhou, Yuancai Zhao, et al. Leak Resistance techniques of thief zone cementing in domestic oil and gas fields [J]. Natural Gas Industry, 2005, 25 (6): 45-48.

[2] Yang Wu, Zhihai Xiao, Xiaogang Shen, et al. Study on well cementing techniques for wells with lost circulation in Jingnan area [J]. Drilling Fluid and Completion Fluid, 2017, 34 (06), 95-99.

[3] Low N, Daccord G, Bedel J P. Designing fibered cement slurries for lost circulation applications: case histories [C]. SPE 84617, 2003.

[4] Deyu Wang, Xiaolin Pu, Taihe Shi, et al. Introduction and evaluation of mode dl-1 device for lost circulation control [J]. Oil Drilling and Production Technology, 1996, 18 (5): 44-48.

[5] Yuguo Hu, Jicun Yuan. Application of plugging materials for lost circulation in petroleum drlling [J]. Drilling Fluid and Completion Fluid, 2000, 17 (3): 38-40.

[6] Zhengguo Zhao, Xiaolin Pu, GuWang, et al. Bridge plug plugging drilling fluid technology of fractured leakage [J]. Drilling Fluid and Completion Fluid, 2012, 29 (3): 44-46.

[7] Don Whitfill. Lost circulation material selection, particle size distribution and fracture modeling with fracture simulation software [C]. SPE115039, 2008.

[8] Dang D H, Gao F, He J Y, et al. Research and application of cement plugging techniques in evaporite bed of piedmont tectonic belt of the Tarim Basin [J]. Advanced Materials Research, 2013, 807-809: 2634-2638.

[9] Huajie Liu, Yuhuan Bu, Jay G. Sanjayan, et al. The application of coated superabsorbent polymer in well cement for plugging the microcrack [J]. Construction and Building Materials, 2016, 104: 72-84.

[10] Jianlong Zou, Jiansheng Qu, Guangming Lv, et al. Laboratory evaluation of fiber cement in resuming lost circulation [J]. Drilling Fluid and Completion Fluid, 2007, 24 (2): 42-44.

[11] Yili Kang, Kaicheng Wang, Chengyuan $\mathrm{Xu}$, et al. High-temperature aging property evaluation of lost circulation materials in deep and ultra-deep well drilling [J]. Acta Petrolei Sinica, 2019, 42 (2): 215-223.

[12] Effendhy, Junaidi H, Abbas R, et al. Fibers in cement form network to cure lost circulation [J]. World Oil. 2003, 224 (6): 48-50.

[13] El-Hassan H I, Abbas R, Munk T. Using a novel fiber cement system to control lost circulation: case histories from the middle east and the far east [C]. SPE 85324, 2003. 
[14] Tingting Yu, Jianmin Deng, Jian Li. Laboratory research on use of fiber cement slurry to prevent lost circulation [J]. Oil Drilling and Production Technology, 2007, 29 (4): 89-91.

[15] Tingting Yu, Jianmin Deng, Jian Li, et al. Research on the High Density Cement Slurry Containing Fibers [J]. Drilling Fluid and Completion Fluid, 2008, 25 (2): 40-42.
[16] Sudong Hua, Xiao Yao, Huajun Zhu, et al. Anti-lost-circulation performance evaluation and function mechanism of fiber slurry system [J]. Journal of China University of Petroleum, 2012, 36 (1): 158-161. 